\title{
LAS CUENTISTAS DE LA LITERATURA FANTÁSTICA PERUANA EN EL SIGLO XXI: RESURRECCIONES E INSURRECCIONES
}

\author{
Audrey LOUYER \\ Université de Reims Champagne-Ardenne \\ audrey.louyer@orange.fr
}

Recibido: 12-08-2020

Aceptado: 27-04-2021

(c) $\underset{\mathrm{Br}}{(1)}$

RESUMEN

La tradición realista peruana ocultó durante muchas décadas el reconocimiento de la literatura fantástica publicada en el país a lo largo del siglo xx. Parece que pasó algo similar con la reducida representación de las autoras peruanas en la escena literaria nacional. Este trabajo se centra más precisamente en el cuento fantástico escrito por mujeres y reflexiona sobre la evolución de las tendencias, entre tradición e innovación, entre poesía alegórica y afirmación histórica, en unas escritoras que son grandes protagonistas del siglo XXI.

PALABRAS ClAVE: narrativa breve peruana; literatura de mujer; lo fantástico; narrativa del siglo $\mathrm{xx}$.

\section{WOMEN WRITERS OF PERUVIAN FANTASTIC SHORT STORY OF THE 21ST CENTURY: RESURRECTIONS AND INSURRECTIONS}

\section{AbSTRACT}

Peruvian realist tradition concealed for many decades the recognition of the fantastic literature published in the country throughout the 20th century. It seems that something similar happened with the reduced representation of Peruvian women writers on the national literary scene. This work focuses more precisely on the fantastic short 
stories written by female authors and their evolution, between tradition and innovation, between allegorical poetry and historical affirmation, being the work of several women writers who are great protagonists of the 21st century.

KEY-WORDS: Peruvian short stories; women's literature; the fantastic; 21st century fiction.

La tradición realista, el paulatino desarrollo de las casas editoriales y la contemporaneidad de las autoras de lo fantástico del siglo xxi hacen difícil la necesaria tarea de identificarlas y estudiar su poética. En efecto, las hay que publican textos sueltos en antologías, otras que integran textos fantásticos dentro de un libro de cuentos en medio de otras tonalidades, las hay que reivindican esta escritura al aceptar ser consideradas «autoras de lo fantástico». Esto plantea de entrada la dificultad de las denominaciones, de los límites y las fronteras entre los géneros, la definición de lo real, lo fantástico y lo imposible en una sociedad que convive con una forma de magia en lo cotidiano, y las nociones de mito y de historia. Por otra parte, en una dinámica actual marcada por los movimientos feministas contestatarios, resulta imprescindible pensar estos textos y contextos con matices para revelar su riqueza y evitar los atajos y las reducciones conceptuales. ¿En qué medida las dos primeras décadas del siglo XxI ilustran una afirmación y un reconocimiento de las autoras que no se basa en una afirmación del género sino en un diálogo con la marcada tradición realista peruana, y qué poética permite expresar esta afirmación? En un primer momento, veremos por qué las mujeres de lo fantástico cuentan con una representación reducida en el panorama literario nacional e internacional. Ahora bien, al constituir nuestro corpus, que se basa en unas quince autoras contemporáneas, cuya selección justificaremos a lo largo del estudio, veremos entre ellas puntos en común, en una poética que adopta y renueva la tradición del cuento fantástico clásico. Sin embargo, hay que tener en cuenta unos particularismos locales que pueden tener ecos universales, lo que será la base de la última parte de este trabajo. 


\section{UNA REPRESENTACIÓN REDUCIDA EN EL PANORAMA LITERARIO}

La historia literaria nacional queda marcada por la hegemonía del realismo en el Perú en los siglos XIX y xx. La afirmación de la singularidad del territorio se expresó mediante historias verosímiles. Además, el Perú manifiesta una heterogeneidad cultural que invita a una nueva comprensión de lo andino, de ahí el desarrollo, por ejemplo, de la literatura indigenista, entre cuyos grandes autores figura una mujer, Clorinda Matto de Turner, con Aves sin nido (1889). A este respecto, también hay que subrayar que la literatura peruana se articuló con los procesos históricos y políticos. Antonio Cornejo Polar (1989), al insistir sobre la multiplicidad de las historias en el continente latinoamericano, recorrió las grandes etapas de la literatura de la Independencia, el Costumbrismo, el Incaísmo, es decir, unos rasgos de la escritura que constituyen los cimientos de la tradición literaria nacional.

Y la literatura fantástica peruana se quedó en la sombra, lo que no favoreció su identificación o su reconocimiento en la medida en que, por lo general, es un modo de expresión literaria que se afirma en la marginalidad. Por una parte, esta proximidad entre historia y proceso literario implicó un predominio del ensayo y de la novela, dos géneros en los cuales lo fantástico, que más tiende a funcionar con el formato del cuento, no encontró una vía de expresión. Por otra parte, si es verdad que Ricardo Palma integra en sus Tradiciones elementos que pueden parecer fantásticos como en «La esquina del muerto», «Traslado a Judas», «Dónde y cómo el diablo perdió el poncho» o «El encapuchado», podemos considerar que se asimilan más bien, en su tonalidad general, con lo maravilloso-cristiano. Por último, las antologías de cuentos fantásticos hispanoamericanos como la de Phillipps-López (2003) o Martínez (2011) solo integran, entre los peruanos, menciones o cuentos de Clemente Palma, lo que manifiesta el reconocimiento relativo de los peruanos en el continente fantástico.

Ahora bien: autores peruanos famosos como César Vallejo o Abraham Valdelomar escribieron algunos cuentos fantásticos, lo que inició la constitución de una tradición que rescataron críticos como Harry Belevan o Elton Honores en los siglos xx y xxI. Gracias a ellos, constatamos que se mantuvo lo fantástico a lo largo del siglo xx: basta con recordar algunos cuentos de Julio Ramón Ribeyro o de José B. Adolph. Y esta presencia insistente, a nuestro parecer, se explica porque el efecto fantástico no funciona sin un efecto de lo real, un marco de verosimilitud como lo define Roland Barthes, para que luego surja lo imposible, lo inadmisible. Por eso, hasta los autores más realistas 
han podido cultivar la vena de lo fantástico, como Carlos Calderón Fajardo por ejemplo. Para este trabajo, nos basamos en una definición de lo fantástico que se sitúa en la línea de los estudios de Ana María Barrenechea (1972), Rosalba Campra (2008) y David Roas (2011): ${ }^{1}$ consideramos que el efecto fantástico nace de la descripción o de la sugestión de un encuentro problemático entre dos planos, lo real y lo imposible, que plantea mediante un trabajo del lenguaje un enigma insoluble, con pasajes de un plano a otro.

A pesar del rescate de los autores fantásticos en el panorama literario, la identificación y el reconocimiento de mujeres escritoras de esta modalidad queda limitado. Es verdad que Carlota Carballo de Núñez y María Tellería Solari fueron autoras que participaron de la constitución de un canon del siglo xx, así como Sara María Larrabure (famosa por su retrato pintado por Salvador Dalí) con el cuento «Peligro», de 1957. En términos de poética, los cuentos de estas escritoras obedecían a una estructura bastante común a los autores de su época. En la antología de 1977 de Harry Belevan dedicada a los cuentos fantásticos peruanos, entre los veinte autores seleccionados, aparecían los cuentos de dos mujeres: «El pájaro dorado o la mujer que vivía bajo el árbol del pan» de Carlota Carvallo de Núñez y «La apoteosis de la maestra» de María Tellería Solari. Más tarde, en el primer tomo de los 17 fantásticos cuentos peruanos (2008) de Gabriel Rimachi Sialer y Carlos Sotomayor, no aparece ninguna mujer; en el segundo tomo, publicado en 2012, solo son tres. Mientras tanto, Gonzalo Portals, en La estirpe del ensueño, en 2009, presenta textos de autoras de la narrativa del 50 y, dentro de una categoría titulada «Lo insólito», recopila los cuentos de tres autoras: Pilar Dughi, Rocío Silva Santisteban y Tanya Tynjälä, única peruana presente en la antología española y latinoamericana de mujeres Insólitas (2019), a cargo de Teresa López-Pellisa y Ricard Ruiz Garzón. Por último, Horrendos y fascinantes (2013) consta de veintisiete textos, dos de los cuales fueron escritos por mujeres. Hasta en Tenebra, muestra de cuentos peruanos de terror, de Carlos Enrique Saldívar (2017), solo tres de los quince textos son escritos por mujeres. Estos elementos ilustran la dificultad para identificar un canon de autoras del siglo XXI.

Además, en ciertas antologías, la selección puede resultar sorprendente dada la definición amplia de lo fantástico. Acerquémonos a Más allá de lo real, de Elton Honores (2018): solo aparecen tres mujeres de un total de

1 Tenemos en cuenta los aportes de las dos primeras críticas, que cuestionan y actualizan la noción clásica de transgresión y duda tradicionalmente asociada con la propuesta teórica de Tzvetan Todorov (1970). También sabemos que el sentimiento de duda ya no es típico del personaje, sino que puede ser experimentado por el propio lector. El trabajo de David Roas permite determinar cuatro rasgos esenciales de lo fantástico: lo real (o la idea que tenemos de lo real), lo imposible, el miedo y el lenguaje. 
dieciocho autores. Y entre estos tres textos, el de Karina Pacheco, «El violinista de las montañas», no es a nuestro parecer el cuento más representativo de la autora en su exploración del efecto fantástico; se trata más bien de un cuento maravilloso-alegórico con ecos del cuento tradicional «El flautista de Hamelin» que un texto fantástico, en la medida en que no cuestiona la percepción de lo real.

Se trata de un canon en construcción con la doble marginalidad de mujer y fantástico; en su dinámica, observamos un doble movimiento: mediante libros de cuentos individuales y, por otra parte, antologías que asumen el punto común de las mujeres autoras o el de la escritura fantástica. En raras ocasiones, como es el caso de Yeniva Fernández, notamos una homogeneidad del libro completo en su escritura fantástica. Pero en muchos casos, las autoras cuentan con algunos textos fantásticos, entre otros más realistas: es el caso de Claudia Salazar Jiménez o Pilar Dughi. Cabe señalar que determinadas antologías peruanas recientes se dedican por completo a las mujeres, como es el caso de Una voz que existe (2019), a cargo de Carmen Ollé, y de los dos proyectos Ucrónica, crónicas alternativas peruanas (2020) y 21. Relatos sobre mujeres que lucharon por la independencia del Perú (2021). Además, la editorial peruana Maquinaciones reeditó en 2019 un volumen de una cuentista peruana, Lastenia Larriva de Llona (1848-1924), lo que muestra el interés por las autoras del pasado literario nacional; un número notable de sus cuentos son de orientación fantástica.

Este rápido panorama nos sirve de base para adentrarnos ahora en los textos y en su poética. Pero antes, para sintetizarlo, proponemos un esquema-balance ${ }^{2}$ de las tonalidades dominantes de los textos que seleccionamos, para mostrar su relativa proximidad. Podemos determinar dos familias principales de cuentos. Un primer grupo derivaría de la inscripción en el realismo y otro, de una escritura fantástica en su sentido más ancestral. En el grupo de los textos heredados de la escritura realista podríamos destacar dos ramas: una recreación de una realidad segunda, con la ciencia ficción de Tanya Tynjälä o de Alejandra P. Demarini por ejemplo, y una exageración barroca que desemboca ora en el horror como miedo extremo en el cuento de Liliana Flores Vega «La criatura de los humedales», ora en lo grotesco como humor extremo si pensamos en «Disección», de Yelinna Pulliti.

Lo fantástico ancestral presenta también dos tendencias principales: la expresión poética, metafórica y alegórica que veremos en el cuento de Marcia

2 Sobre el recurso a la cladística para la clasificación, véase Louyer (2016: 31-35). 
Morales Montesinos «La chica de la encrucijada»y, por otra parte, una serie de cuentos que implican un tipo de investigación del lector en la medida en que el texto fantástico invita a constatar el encuentro entre lo real y lo imposible. Si se resuelve el enigma, desembocamos en el relato de tipo policíaco: «El mensaje», de Pilar Dughi, ilustra este grupo. Pero si no se resuelve el enigma, se puede admitir lo insólito de la situación, como es el caso en varios cuentos de Rossana Sala, ${ }^{3}$ o en el relato de Laura Riesco que estudiaremos a continuación. Si no se admite (por parte del personaje o del lector) la situación insoluble del enigma planteado, estamos frente a un texto fantástico en su estado más completo, que logra provocar el sentimiento de inquietante extrañeza, el unheimliche freudiano: es un efecto que logran los cuentos de Alina Gadea y Yeniva Fernández.

Ahora bien: esta aproximación obliga a considerar el cuento como un objeto globalmente homogéneo que podríamos encasillar en una categoría determinada: esta clasificación puede ser útil para revelar la relativa proximidad entre los textos, pero también hay que ver cómo funcionan estos cuentos desde el punto de vista de la sintaxis de lo fantástico, de su poética. En efecto, al leer los textos nos damos cuenta de que las fronteras son porosas: por ejemplo, el cuento de Yelinna Pulliti «Conversación en el cementerio» (Honores, 2018) recuerda en varias ocasiones la narrativa de Juan Rulfo y el realismo mágico. Ahora bien, la atmósfera, el juego de focalizaciones, el motivo de la sonrisa diabólica, el recurso lingüístico al «como si», vector hacia lo imposible, son elementos que facilitan el efecto fantástico. Pero es verdad que la ausencia de problematización del evento imposible nos lleva a considerar el texto como parte del realismo mágico.

Así pues, esta primera aproximación da cuenta de una fuerte propensión al desarrollo del realismo en la narrativa peruana y, como consecuencia, una literatura fantástica que quedó en la sombra: pero ahí moran también las sombras de unas mujeres que escriben y publican. Toca ahora estudiar más detalladamente el funcionamiento del efecto fantástico en su escritura.

3 Rossana Sala propone un libro de cuentos marcado por la infancia, los colores, la imaginación, el luto y cómo superarlo desde la perspectiva de una niña («Sed»). El cuento que cierra el libro, «¿Nos acompaña a una taza de té?» ilustra el efecto fantástico en un juego intertextual: por una parte, con una alusión directa y explicita a Raymond Carver, y, por otra parte, el recuerdo del famoso cuento de Julio Ramón Ribeyro «Ridder y el pisapeles». Lo fantástico del lenguaje también aparece en «El cerco» mediante el recurso a la autorreflexividad y la metalepsis: «Me veo a mí mismo sentado en la mesa y el duende me mira... me mira y me pide que escriba por fin este cuento» (Sala, 2016: 80). 

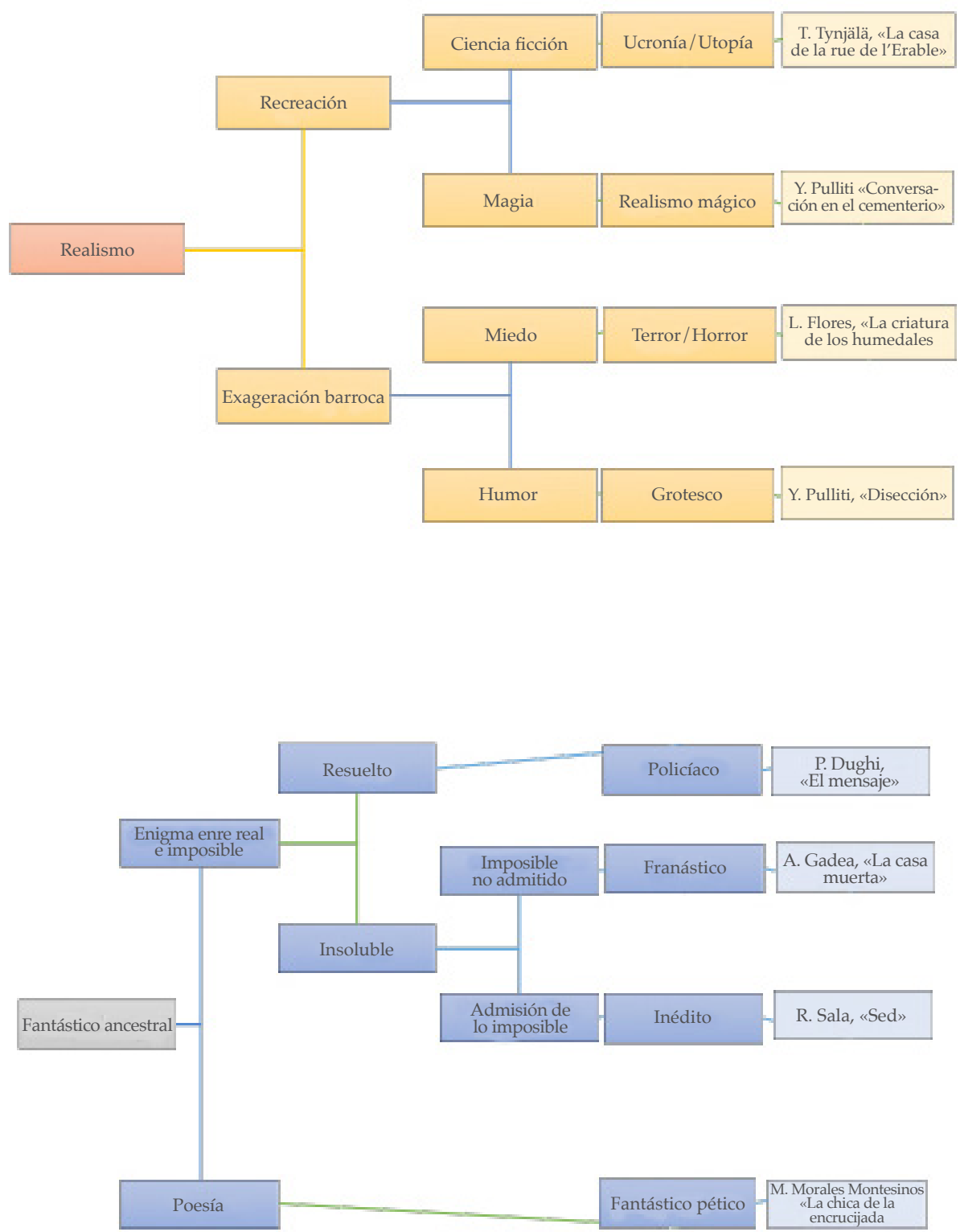
Después de haber determinado las grandes líneas en el terreno de elaboración de la historia literaria de lo fantástico peruano escrito por mujeres, hace falta estudiar su poética, para determinar en qué medida ellas proponen nuevas aproximaciones al modo de expresión fantástico. Si, por una parte, siguen con las técnicas clásicas, cabe notar que los recursos de la «écriture féminine» también aparecen en algunas autoras y permiten otra mirada que prolonga esta escritura clásica.

Para estudiar lo fantástico en el lenguaje, nos basaremos en cuatro autoras que tienen puntos en común en su escritura: Blanca Miosi, Yeniva Fernández, Laura Riesco y Alina Gadea. Todas ellas cultivan una expresión fantástica situada en la línea del cuento tradicional, como lo define Julio Cortázar al evocar su esfericidad:

La noción de pequeño ambiente da su sentido más hondo al consejo, al definir la forma cerrada del cuento, lo que ya en otra ocasión he llamado su esfericidad; pero a esa noción se suma otra igualmente significativa, la de que el narrador pudo haber sido uno de los personajes, es decir que la situación narrativa en sí debe nacer y darse dentro de la esfera, trabajando del interior hacia el exterior, sin que los límites del relato se vean trazados como quien modela una esfera de arcilla. Dicho de otro modo, el sentimiento de la esfera debe preexistir de alguna manera al acto de escribir el cuento, como si el narrador, sometido por la forma que asume, se moviera implícitamente en ella y la llevara a su extrema tensión, lo que hace precisamente la perfección de la forma esférica (1969: 59-60).

Laura Riesco (1940-2008) parece adoptar este proceso y actualiza la escritura fantástica en un contexto contemporáneo, urbano, con el personaje horrible de la gran ciudad norteamericana, marcando la desilusión frente al sueño americano. Publicó una novela que la hizo famosa en 1994, Ximena de los caminos, y su prosa ha sido valorada por especialistas ${ }^{4}$ de la narrativa peruana. «El niño y la mañana» (González Vigil, 2013: 63-80) casi podría ser un cuento realista pero, en las últimas páginas, aparecen unas alusiones extrañamente familiares al clima, al silencio, a los coches, al ambiente del principio; esta estrategia narrativa justifica la acumulación inicial de detalles y recuerda en su

4 Ricardo González Vigil recopila un cuento suyo en su antología que abarca de 2001 a 2010, y afirma: «Publicó poco, pero de una calidad fuera de lo común, tanto por la fluidez de su prosa y la expresividad de sus variados recursos narrativos, como por la penetración psicológica y la sutileza para retratar el entorno sociocultural con sus tensiones y fricciones entre lo andino y lo occidental, la lucha de clases, el racismo y el machismo» (2013: 62). 
técnica la mención del parque de los robles y de los ventanales de «Continuidad de los parques» hasta el efecto final. «Cuando a cierta distancia ve un carro rojo conducido por una mujer que viaja sola» (González Vigil, 2013: 79) constituye la frase bisagra que provoca el efecto de repetición, con un cambio de punto de vista, un cambio de papeles, del engañado al engañador.

El segundo aspecto que comparten las autoras es la importancia de la percepción y de la duda que cuestiona esta percepción. Blanca Miosi publicó El piso de la calle Ryden y otros cuentos de misterio en 2014. El cuento epónimo es de factura muy clásica, lo que puede sorprender en un texto publicado en pleno siglo xxI. La duda característica tal y como la presenta Tzvetan Todorov (1970) entre lo maravilloso y lo extraño aparece en este cuento, en el que el nuevo inquilino de una casa se enamora de un ser fantasmal. La duda surge pues en el lector:

La gente se comporta conmigo últimamente de manera extraña, me mira como si estuviera enfermo, pero me siento mejor que nunca. Pienso que nunca fui un hombre tan feliz y tan amado. Sé que es una locura, pero estoy enamorado, y aunque solo pueda verla y sentirla por las noches en mi cama, me conformo con eso. Hago el amor con ella dos, tres veces cada noche, y sé que ella está satisfecha, lo sé porque me lo dice constantemente. No como ni duermo, y durante el día camino como un sonámbulo (Miosi, 2014).

Yeniva Fernández es una de las autoras de la generación del siglo XXI que empieza a beneficiarse de un interés a escala internacional. Publicó dos libros de cuentos, Trampas para incautos (2009) y Siete paseos por la niebla (2015). El cuento «Rutka o la historia de algunas flores extrañas» se basa en la duda, frente a un fenómeno problemático que plantea un enigma entre el motivo explicable - los efectos de la fiebre debida al sarampión en la protagonistay el motivo sobrenatural: la tía de Rutka es un monstruo (Fernández, 2015: 47-68). Laura Riesco mezcla también el sueño y la vigilia («Como sonámbula dentro de un mal sueño llega a la cocina»; González Vigil, 2013: 79). Alina Gadea, en «La casa muerta» (Donayre, 2013: 193-221) también desarrolla esta duda tras escuchar unos ruidos raros: «¿Sería ese muchacho un fantasma viviente? ¿Sería la señora con los espectros del ático muerto? ¿O serían solo sueños?» (Donayre, 2013: 215). ${ }^{5}$ Por eso, no estamos totalmente de acuerdo cuando afirma Honores que:

5 «Sentí que alguien se acercaba, pero no llegué a ver a nadie. Debía ser un gato detrás de alguna pared» (Donayre, 2013: 206). En el mismo cuento, ilustra esta vez una percepción sensorial relacionada con la vista. 
La narrativa fantástica es un tipo de relato en el que se representan hechos o acontecimientos imposibles (desde el punto de vista del mundo realista representado, universo que es semejante al del lector) que ocurren de modo fáctico (no son alucinaciones o errores de percepción de los personajes o del narrador) y que están más allá de cualquier explicación lógico-racional (2018: 16).

El autor parece rechazar toda la herencia de lo fantástico de percepción del cuento tradicional, que sí cuajó entre estas autoras.

El tercer aspecto que comparten las autoras en su escritura es una inscripción en la gran ciudad hostil al desarrollo humano en una escritura que convierte lo urbano en un espacio que crea el malestar. En el caso de Fernández y Gadea, se trata explícitamente de Lima. Es lo que sobresale en «Con Yolanda en el acantilado» (Fernández, 2015: 103-112), o en el cuento de «Rutka o la historia de unas flores extraordinarias», entre Miraflores, la huaca Pucllana, o las largas avenidas con tráfico como Javier Prado. En el cuento de Gadea, la protagonista se enamora de la casa en un contexto de reformas y de boom de la construcción en la capital peruana. En Riesco, de entrada, la mención del adjetivo «septentrional» marca el cambio de lugar y la integración del marco espacial en el hemisferio norte, probablemente los Estados Unidos. Las impresiones sensoriales y las reflexiones sobre el clima favorecen la hostilidad del espacio. Pero más allá, en la repetición del círculo vicioso en el que se basa el texto, leemos la crítica de la deshumanización, de la degradación de las relaciones humanas, de la soledad de los inmigrantes en las grandes urbes norteamericanas y al mismo tiempo una sátira de la que el lector, finalmente, se convierte en el testigo cómplice. Yeniva Fernández, por su parte, interroga finalmente la estigmatización, el rechazo, la crueldad y cierto tipo de racismo, convocando un sentimiento de miedo que sigue vigente en el siglo XXI sin necesitar los recursos del horror de las descripciones sangrientas: basta con el arte de la sugerencia y un hábil manejo del lenguaje para que cuaje el efecto fantástico en el lector. Estos ejemplos permiten afirmar que varias autoras contemporáneas ilustran la continuidad con un fantástico del lenguaje: esfericidad del relato, duda sobre la percepción y transfiguración del espacio en una descripción que favorece la epifanía del elemento imposible.

Ahora bien, las autoras del siglo xxI no solo reproducen técnicas clásicas, sino que también transforman los motivos tradicionales. A raíz de este aspecto se suman nuevas autoras al análisis: Rossana Sala, Liliana Flores Vega y Kathy Serrano. El primer motivo que llama nuestra atención es la casa. Si Miosi y Gadea la tratan de una forma similar a la de Silvina Ocampo en «La 
casa de azúcar», superan el tópico clásico del locus terribilis. Gadea, por ejemplo, opera una evolución desde la comparación típica basada en «como si», que permite crear analogías fértiles, a la metáfora: «Los cuadros colgados y volteados contra la pared eran personas castigadas» (Donayre, 2013: 208) e insiste sobre la asimilación casa/personaje: «Las ventanas de las buhardillas dejaron su aspecto de ojos soñolientos y volvieron a mirar el mar después de muchos años» (Donayre, 2013: 212). Estos elementos añaden una coloración lírica a la descripción del ambiente fantástico del lugar. Kathy Serrano, en «Retorno» propone un microrrelato con tono de humor negro, donde la casa se convierte en una especie de ataúd: «La familia ahora es como ella la soñó, y lo mejor de todo es que ya ninguno respira» (2019: 159).

El segundo motivo que actualizan las autoras es el monstruo. Es un motivo «límite» en la escritura fantástica en la medida en que su uso puede llevar a la desaparición del efecto fantástico para caer en lo grotesco o el cuento de hadas. En «La criatura de los humedales», Liliana Flores Vega elabora el sentimiento de miedo mediante la aparición del monstruo clásico («Una cosa tan antigua que no tiene nombre»; Saldívar, 2017); la vacilación la siente el propio lector en la medida en que la narradora reivindica el hecho imposible («Necesito ordenar los extraños acontecimientos que sucedieron durante el último fin de semana. No espero que me crean, tampoco me importa si me juzgan como loca»; Saldívar, 2017). Lo que nos llama la atención es que no es el mismo tipo de monstruo que el ser del final de la novela La piedra en el agua, de Harry Belevan (el monstruo de la imaginación, del sueño de la razón) sino de un ser relacionado con el pasado del lugar, inscrito en el espacio natural en el que están los personajes. Del mismo modo, el monstruo del cuento de Yeniva Fernández mencionado anteriormente causa terror, pero también fascinación en la niña. Esta idea nos recuerda la manera como Richter percibe la metamorfosis desde el punto de vista femenino, como «un accomplissement débarrassé de réflexions et de paroles inutiles, une respiration élargie et sereine, non un châtiment, mais une récompense» (1995: 25): se trata de una visión nueva del monstruo, marcada por el mito.

El último motivo tradicional que merece interés en su actualización es el espejo / retrato. Factor de desdoblamiento, deformación y vértigo de la multiplicación infinita, no deja de recordar la obra maestra de Oscar Wilde, The picture of Dorian Gray. En el caso de Rossana Sala, «Mi rostro en el espejo» es un cuento que toma como punto de partida este motivo clásico, pero lo transforma al tomar al pie de la letra la expresión «el vivo retrato», ya que el pintor roba la apariencia de sus modelos. El efecto de coda es radical: «Todo hubiera 
podido considerarse una extravagancia del artista, hasta que intenté encontrar mi rostro en el espejo» (Sala, 2016: 82).

La renovación del cuento fantástico clásico en la perspectiva de la escritura de las mujeres estriba en la importancia dedicada al ser no solamente en sus interacciones con su entorno, sino también en la expresión de su propia percepción interior. Nos dedicaremos finalmente a dos modalidades de esta exploración: el cuerpo y la mente.

Claudia Salazar Jiménez es famosa por su novela La sangre de la auro$r a$, que ganó el premio Las Américas en 2014 y articula ficción e historia en una reflexión sobre el conflicto armado interno, pero desde una perspectiva femenina, un punto de vista que solo recientemente se empieza a tener en cuenta. También publicó un libro de cuentos en 2016, Coordenadas temporales, doce textos diversos entre los cuales destacaremos dos relatos típicamente fantásticos. Para demostrar su original visión nos parece pertinente analizar «En paz» (Salazar Jiménez, 2016: 25-29). La voz narrativa se presenta en focalización interna con un tiempo en presente y unas analepsis, pero nos damos cuenta de que es un cuerpo muerto, o sea un fantasma, el que habla. El efecto fantástico se basa aquí en la subjetividad de la temporalidad, el enfrentamiento entre el tiempo histórico (del telediario o de la sucesión lógica de los eventos a lo largo de cuatro años) y el tiempo subjetivo (lo que la narradora llama «el tiempo del cuerpo» e insiste diciendo «mi cuerpo tenía su propio tiempo»; Salazar Jiménez, 2016: 27). Al considerar que el lenguaje permite concebir de forma menos espantosa lo inadmisible, en concreto el hecho de morir, la narradora propone una descripción interna del fenómeno de la muerte física: «He sido consciente de todo lo que les pasaba a mis tejidos y órganos. Ese lento proceso que fluctuaba entre la rigidez, lo líquido, luego lo blando y la rigidez nuevamente. Aun así, no sufría. No sentí dolor. Esto de no respirar es extraño pero, si consideramos el resultado olfativo de todo lo que se iba licuando en mí, es lo mejor» (Salazar Jiménez, 2016: 26). La voz de ultratumba, que todavía está en el limbo, se dirige a sus lectores con un testimonio preciso, no sin un toque de picardía. El final del cuento mezcla lo grotesco y lo cínico, ya que el trabajo de los paramédicos no se presenta desde un punto de vista externo -o interno en uno de los policías, por ejemplo- sino desde el punto de vista de la víctima y sus sensaciones corporales, visuales, auditivas. En «Disección», Yelinna Pulliti Carrasco admite del mismo modo lo imposible desde la primera línea: «Ahora estoy convertido en fantasma contemplando mi propio cuerpo inerte, tendido sobre una mesa, entre muchos otros» (Saldívar, 
2017). La descripción del cuerpo mutilado puede despertar asco en el lector. Llama la atención el hábil manejo de las estrategias de narración con la primera persona y el monólogo, así como la irrupción del discurso directo. Esta forma de expresión nos recuerda lo que describe Richter a propósito de Woolf en Orlando: «Le monde et son corps, son corps dans le monde ne lui appartiennent plus jamais vraiment. Par réaction, Virginia se créa un univers intérieur compensatoire qui la protégeait contre les agressions environnantes» (2017: 49-50). La idea de desdoblamiento, pero presentado de esta forma original, remite a lo que Armitt expresa con la idea de «écriture féminine», como eco de la teoría de Cixous:

both layers speak together to give voice to the «real» ghost of the text which might be read as a form of écriture féminine / writing the body which, in this case, also functions as a body of articulation - the underlying, occulted voice speaking through a surface level of conformity (Armitt, 2000: 103).

Respecto a los meandros del pensamiento y su interacción con lo fantástico, pensamos en dos autoras representativas. Pilar Dughi se graduó en psiquiatría, lo que influye sobre su escritura en la elaboración de los personajes de sus relatos. Una edición completa de sus cuentos, en 2017, permite observar la evolución de su carrera literaria. La especificidad de su escritura en la manera de tratar lo fantástico se observa en «El mensaje», un cuento que ya había sido seleccionado por Gonzalo Portals en su antología La estirpe del ensueño en 2009. En este texto, opera lo fantástico a lo Kafka, ya conceptualizado por Jean-Paul Sartre en «Aminadab ou du fantastique considéré comme un langage». ${ }^{6}$ «El mensaje» (2017: 29-33) explora los equívocos del lenguaje. Pueden basarse en el sentido doble de las palabras especulares o ambiguas, o las oraciones ambiguas, que insertan brechas en la lógica de deducción que elabora el lector a lo largo de su investigación. La estrategia de la construcción de este cuento usa palabras bisagra que manifiestan una progresiva inversión de las fuerzas entre los personajes. El relato lo asume un narrador heterodiegético a través de un punto de vista interno, lo que resulta sorprendente - y hasta paradójicopuesto que, en general, se suele preferir un relato en primera persona para

6 «[Kafka et Blanchot] ont supprimé le regard des anges, ils ont plongé le lecteur dans le monde, avec K., avec Thomas; mais, au sein de cette immanence, ils ont laissé flotter comme un fantôme de transcendance. Les ustensiles, les actes, les fins, tout nous est familier, et nous sommes avec eux dans un tel rapport d'intimité que nous les percevons à peine; mais, dans le moment même où nous nous sentons enfermés avec eux dans une chaude atmosphère de sympathie organique, on nous les présente sous un jour froid et étranger» (Sartre, 1947: 127). 
permitir la identificación del lector. La última oración del texto da la última vuelta de tuerca de forma hábil: la originalidad del cuento de Dughi es que la expresión fantástica cuestiona la elaboración deductiva del protagonista y del lector. La formación de siquiatra de la autora favorece una exploración original del tema. Este laberinto de la mente relacionado con lo fantástico lo desarrolla hasta el punto de la locura Julie de Trazegnies (1973- 2015), en «Sin retorno». Es un texto que también fue seleccionado para el segundo tomo de la antología 17 fantásticos cuentos peruanos (Rimachi Sialer y Sotomayor, 2012: 105-118). La narradora cree que está teniendo una pesadilla, pero al final del texto opera lo que podríamos llamar una «trampa de la verosimilitud», o un falso efecto de lo real que crea una ilusión: el sueño y las proyecciones de locura de la protagonista se parecen tanto a lo cotidiano que el lector no se da cuenta de que se trata de los pensamientos de la protagonista. Es un relato en primera persona, con focalización interna, lo que crea una situación inicial posible, pero que se invierte al final del texto. A través de una mezcla de analepsis e introspecciones, el texto muestra que cada tentativa para salir de la pesadilla es una etapa más en la locura en la que se sume la protagonista. Se puede entender este proceso como una estrategia de escape frente al dolor de la pérdida de un ser querido. El delirio de la narradora se integra en un testimonio que somete lo «real» a un coeficiente de deformación que empieza con la paranoia y se completa con las impresiones de pesadillas cuestionadas inmediatamente. El final interroga la verosimilitud de las páginas que el lector acaba de descubrir, y la fiabilidad de la narradora: «Quizás ya no estaba más en el mundo en el que había vivido con Morgana y Diego, o quizás — ahora pienso- ese mundo jamás existió» (Rimachi Sialer y Sotomayor, 2012: 118). El lector presencia esta locura como testigo y tiene que acompañarla hasta el efecto de twist ending. Richter describe el mismo tipo de fenómeno a propósito de Karen Blixen: «recherchant sa vérité par le truchement d'un mensonge provisoire, elle bouscule, malmène et renverse le sens commun des choses pour arriver paradoxalement à leur réalité profonde» (2017: 18).

Así, el trabajo del lenguaje articulado con el efecto fantástico también se manifiesta a través de estas exploraciones y experiencias interiores, que renuevan el cuento clásico en la poética de estas autoras. Este modo de expresión también les da una voz a las entidades que quieren confesar lo imposible cuando otras voces callan, o silencian a los demás, de ahí la importancia de tener en cuenta la inscripción histórica de los cuentos y de sus cuentistas. 


\section{Particularismos Locales y ecos universales}

Las autoras de lo fantástico peruano en el siglo XXI no solo siguen con la herencia de los cuentos clásicos, sean góticos o modernos, en una poética de lo fantástico fuera de las preocupaciones locales. La presencia marcada del realismo en la literatura peruana implica en estas narradoras una escritura inscrita en el marco social e histórico, del pasado lejano mítico o de la historia nacional reciente. Pero también supuso la reacción inversa, casi escapista, a través de una escritura que raya con el poema en prosa. Este último apartado del análisis nos permitirá volver a la especificidad peruana de estas dos aproximaciones antagónicas a la escritura fantástica.

En el corpus estudiado, sobresalen dos periodos que constituyen el marco temporal de realización de la acción: una época mítica, entre lo precolombino y la época colonial, y el conflicto armado interno a finales del siglo xx. En ambos casos, el brote del efecto fantástico confiere más dramatismo al evento evocado.

La modalidad fantástica permite hablar de lo imposible, al ser un modo de expresión que puede surgir a raíz de los testimonios y contribuir al trabajo de memoria, por lo cual no es tan «escapista» como se suele tachar a este género a veces relegado al rango de paraliteratura. Después del trabajo de la comisión de la verdad, la memoria histórica se elabora también en el proceso literario — pensemos por ejemplo en La hora azul (2005), de Alonso Cueto, o Abril rojo (2006), de Santiago Roncagliolo-, y el fenómeno que observamos últimamente es la expresión de las voces femeninas que evocan con estrategias literarias nuevas el sufrimiento del cuerpo femenino, entre torturas y violaciones, y sus repercusiones. Como observa Elton Honores (2011: 30): «a partir del ejercicio ficcional, hay un interés de reconstrucción histórica (o mirada hacia el pasado) que permite reflexionar sobre el presente, es decir, se mezcla lo histórico con lo fantástico, reescribe la historia».

Una de las autoras que mejor revelan este aspecto es Rocío Silva Santisteban. Es periodista y defensora de los derechos humanos, y más específicamente de los derechos de la mujer. Ganó dos premios nacionales con sus poemarios Ese oficio no me gusta (1986) y Las hijas del terror (2005). Sus cuentos marcan la voluntad de emancipación, una lucha en contra de las autoridades que abusan de su poder, como vemos en «Reina del manicomio», un texto en el cual la descripción de la locura de la protagonista expresa, con un efecto de contraste, una lucidez que supera las bajezas del director perverso del manicomio donde está encerrada. Carlos Garayar ya le había dedicado a esta auto- 
ra una sección aparte en su artículo a propósito del libro Me perturbas, hablando de «un limpio tránsito del lenguaje de la poesía al de la representación, pero a diferencia de Carmen Ollé, quien al pasar a la prosa atenúa su violencia verbal y amplía sus temas, Silva Santisteban hace aún más agresivo su lenguaje y profundiza en su visión trágica, sangrienta, del amor» (1999: 153). En Reina del manicomio (2013) se mantiene esta agresividad e indignación a través de un lenguaje violento, cruel, crudo también, hasta en los textos fantásticos. Destacaremos al respecto el cuento «NN» (2013: 117-123), donde alcanzamos los límites del horror. El lector descubre con una focalización en el interior de un cuerpo lo que sufre un ser violado, torturado, mutilado al que el narrador le presta una voz - fenómeno que ahora conocemos- para que dé cuenta de las emociones e impresiones físicas. Lo imposible estriba en el alto grado de violencia sufrido por un cuerpo que nunca podría mantenerse vivo para testimoniar. Alcanzamos unas sinestesias del límite:

Vuelve [sic] a repetirse los resplandores, como si se tratase de relámpagos, relámpagos que revientan en sus córneas, relámpagos que se derriten desde el iris y pasan a través del cristalino y se derraman por el nervio óptico hasta llegar a la sección más íntima de su cerebro, allí donde los sentimientos, los afectos y los temores se juntan. Allí revientan esas luces y se convierten en sombras que lastiman sus pensamientos, que laceran sus ideales, que destruyen sus utopías (Silva Santisteban, 2013: 122-123).

La última palabra del texto, «Basta», repetida tres veces, muestra lo insoportable de la descripción de una precisión científica que contrasta con la barbaridad inhumana de los actos. El cuerpo pasivo, que sufre la violación, la destrucción paulatina y sistemática, se expresa a través del texto. Las resonancias con la situación política que sufrió el Perú de los años del conflicto armado interno son evidentes, así como la insurrección en contra de una sociedad donde las voces femeninas quedan ahogadas. En 2012, Christiane Félip Vidal y Cucha del Águila editaron una antología peruana justamente titulada ;Basta! 100 mujeres contra la violencia de género, a raíz del proyecto inicial de la chilena Pía Barros. Silva Santisteban parece inscribirse en esta dinámica.

No olvidemos que ciertas raíces míticas de cuentos contemporáneos proponen resonancias que alcanzan lo universal. Yeniva Fernández parece nutrirse de esos mitos y los integra en sus textos a través de juegos de intertextualidad: véase por ejemplo el paralelismo entre «Axolotl» de Cortázar y «Antes que caiga la noche» en Siete paseos por la niebla. Ahora bien: no se trata de un mero efecto de eco, sino que articula estas figuras míticas con un entorno local 
que el público lector puede identificar fácilmente. En el caso de este cuento, los gatos del Parque Kennedy de Miraflores constituyen un motivo fácil de reconocer en el entorno verosímil y real; ahora bien, cobra su aspecto fantástico al cruzar un modo de escritura que sugiere una migración análoga a la del narrador del famoso cuento de Cortázar. Entre otros ejemplos, recordaremos también el monstruo mitológico a medio camino entre la Medusa y la sirena presente en «Rutka o la historia de unas flores extraordinarias». Las niñas y las mujeres forman el meollo de los personajes del segundo libro de cuentos de la autora. En términos de estrategias narrativas, sentimos la influencia de Poe, de Hoffmann y del propio Cortázar; esta escritura alcanza lo universal por la exploración de los arquetipos míticos. Con esta visión, podemos afirmar que el monstruo no solo da miedo - tampoco se trata de una afirmación del género femenino—, sino que también encarna las posibilidades utópicas universales de forma atemporal, y de esta manera, volvemos a los orígenes: «(T)he woman who is "larger than life" becomes, not a terrifying Gorgon but an empowering utopian possibility, a being not simply physically larger than the norm, but in reputation legendary and thus fabulous» (Armitt, 2000: 14).

Por eso, nos parece que hay que matizar la idea de Honores (2018: 16) cuando afirma que lo fantástico no es una categoría transhistórica: en efecto, algunas autoras alcanzan aspectos universales según la propuesta teórica de François Jullien (2008), en la dinámica de identificación de referentes arquetípicos. El marco de creación del efecto fantástico puede ser localizado, como trasfondo de realización de la acción; también es verdad que el sentimiento de miedo o la relación con los elementos sobrenaturales varían de una cultura a otra. Sin embargo, nos parece posible y necesario identificar unas constantes que se juntan armoniosamente con lo fantástico: las figuras ancestrales (como motivo) y la poesía (como modo de expresión) son dos de ellas. Susana Reisz ya planteó en 2014 la relación problemática que existe entre lo fantástico y la poesía, más allá de la dificultad de definir cada una de estos términos, en la línea de la interrogación presente ya en la teoría de Todorov. Las autoras peruanas contemporáneas ilustran esta posibilidad de combinación, incluso en sus textos en prosa. Veremos primero una modalidad alegórica con Mellet y luego, una apariencia de petit poème en prose con un texto de Marcia Morales Montesinos.

Lo fantástico se articula con la poesía en expresiones a la vez líricas y alegóricas. Un cuento que se sitúa en el límite temporal de los inicios del siglo XXI y manifiesta la vertiente alegórica de lo fantástico es «La mujer alada», de Viviana Mellet (González Vigil, 2001: 671-675). Su cuento fue seleccionado 
en la antología 17 narradoras latinoamericanas, de 1996, bajo el auspicio de CERLALC / UNESCO. Notamos en este texto la paulatina evolución de la escritura entre la poesía y la prosa. La tonalidad poética se nota de entrada en el epígrafe con los últimos versos del poema «Serenata», de Manuel Scorza. La imagen trabajada a lo largo del texto es la de la emancipación femenina en una sociedad patriarcal en la cual el libre albedrío de la mujer queda sometido a la conformidad con la opinión del esposo. Es un cuento alegórico en la medida en que mezcla permanentemente sentido concreto y sentido abstracto. La construcción narrativa supone una progresiva identificación de las características de lo que es una mujer alada: «Hasta que aprendió la lección y ya nunca más intentó audacias como aventurar sus opiniones, manifestar sus deseos, rebelarse contra la autoridad, soñar despierta y otros vicios por el estilo, muy propios de los seres como ella» (González Vigil, 2001: 674). Hay una oscilación entre lo concreto y la imagen, y la síntesis opera dentro de una misma oración: «las alas que la impulsaban a volar no estaban en realidad allí, entre sus omóplatos, sino en un lugar del alma donde nadie las puede cortar» (González Vigil, 2001: 675). El cuento desarrolla finalmente la amenaza que representa el deseo de libertad, materializado por el deseo de volar. Esta imagen recuerda el sueño de Ícaro y su destino trágico. El punto de vista omnisciente del narrador evoca el cuento maravilloso, y el final del relato remite a la oralidad y a la dimensión abierta que también caracterizan los cuentos: «Pero, en realidad, el final de esta historia no existe. O existen, en todo caso, diversos desenlaces para elegir» (González Vigil, 2001: 675). Ahora bien, lo que justifica la integración del texto en el ámbito de lo fantástico es el hecho de tomar al pie de la palabra expresiones figuradas, o concretizar las metáforas. Además, la poesía puede ser considerada como una escritura que, al crear imágenes, va en contra del escollo de la categorización, tal y como propone lo fantástico al invitar al lector a un cambio de paradigma.

No es solo una cuestión de imágenes y alegorías, sino también de la posibilidad de crear poemas en prosa. Marcia Morales Montesinos (Saldívar, 2017) ofrece con «La chica de la encrucijada» un relato corto que se asemeja a la tonalidad de otra autora contemporánea, la salvadoreña Claudia Hernández, en De fronteras o La canción del mar, por ejemplo. El formato es el microrrelato, que otorga a las palabras una concentración del sentido y una polisemia interpretativa («diablo», «pelirrojos» o «descomposición» en el caso concreto). En pocas palabras, la autora logra una alternancia de puntos de vista, entre la subjetividad del protagonista y la crónica dramática del periodista. La descripción mezcla lo real y lo imposible, y el sentimiento de miedo cruzado con 
la apariencia fantasmal del personaje femenino crean la atmósfera clásica de lo fantástico. Lo imposible estriba en el último párrafo, donde se concentra la fuerza poética: «Desde ese día, cada vez que pasa por la "Encrucijada del diablo", Jano vuelve a ver a la muchacha pelirroja, él detiene el auto y corre en su ayuda, pero al querer agarrarla e introducirla al vehículo sus manos se tiñen de sangre y esta desaparece entre sollozos» (Saldívar, 2017). El texto supera lo fantástico tradicional ya que denuncia, a través de la modalidad poética, la realidad de las violaciones y la violencia de género, que se han convertido en asuntos casi triviales y cuya abominación puede saltar a la vista cuando se inserta dentro del relato la sorpresa de un suceso imposible y extraordinario, llamando la atención del lector y devolviéndole al asunto original, desafortunadamente real y bestial: su carácter inadmisible. Así, un fenómeno local cobra una dimensión de denuncia actual e internacional, y la introducción de lo fantástico añade a su vez una dimensión atemporal y desesperadamente eterna; pasamos así de lo local y determinado a lo universal.

Finalmente, queda claro que, en este canon en construcción, las mujeres peruanas ganan terreno: el terreno de lo fantástico sobre el realismo, el terreno de la renovación sobre la tradición, el terreno de la voz femenina sobre una aparente hegemonía masculina. El Perú fantástico también tiene voces femeninas. Y si queremos terminar con un esquema sintético, pero revelador, de las ideas aquí avanzadas, podemos considerar con Armitt (2000: 220) que, en suma, a través de estas mujeres parecen expresarse los arquetipos de Dora y Scheherazade: Dora como raíz de lo gótico femenino («haunted by the phantom of the silenced mother») que encarna la expresión tradicional heredada, por una parte, y, por otra, Scheherazade («refuses to shut up carrying out the framing of her own text and its many characters»), una generación de cuentistas que tienen la capacidad para regenerarse fuera de los modelos y moldes establecidos, dando importancia a las voces calladas para crear nuevos mitos.

\section{BiBLIOGRAFÍA}

ArmitT, Lucie (2000): Contemporary Women's Fiction and the Fantastic, Macmillan Press, Houndmills.

BarrenecheA, Ana María (1972): «Ensayo de una tipología de la literatura fantástica», Revista Iberoamericana, núm. 33/80, pp. 391-403.

Belevan, Harry (ed.) (1977): Antología del cuento fantástico peruano, Universidad Nacional Mayor de San Marcos, Lima. 
- (2017): La piedra en el agua, Animal de invierno, Lima.

CAMPRA, Rosalba (2008): Territorios de la ficción: lo fantástico, Renacimiento, Sevilla.

Cornejo Polar, Antonio (1989): La formación de la tradición literaria en el Perú, Centro de Estudios y Publicaciones, Lima.

Cortázar, Julio (1969): Último round, Siglo XXI, México.

DonAYre, José (ed.) (2013): Horrendos y fascinantes, Altazor, Lima.

Dughi, Pilar (2017): Todos los cuentos, Campo Letrado, Lima.

FERNÁNDEZ, Yeniva (2015): Siete paseos por la niebla, Campo Letrado, Lima.

GARAYAR, Carlos (1999): «Temas y tendencias de la narrativa peruana última escrita por mujeres», en Roland Forgues (ed.), Mujer, creación y problemas de identidad en América latina, Consejo de Publicaciones en la Universidad de los Andes, Mérida, pp. 143-154.

GonZÁLez Vigil, Ricardo (ed.) (2001): El cuento peruano 1990-2000, Copé, Lima.

— (ed.) (2013): El cuento peruano 2001-2010, Copé, Lima.

Honores, Elton (2011): Lo fantástico en Hispanoamérica, Cuerpo de la metáfora, Lima.

- (ed.) (2018): Más allá de lo real: antología del cuento fantástico peruano del siglo XXI, Altazor, Lima.

Jullien, François (2008): De l'universel, de l'uniforme, du commun et du dialogue entre les cultures, Fayard, París.

López-Pellisa, Teresa, y Ricard Ruiz Garzón (eds.) (2019): Insólitas: narradoras de lo fantástico en Latinoamérica y España, Páginas de espuma, Madrid.

Louyer, Audrey (2016): Pasajes de lo fantástico. Propuesta de teoría para un estudio de la literatura de expresión fantástica en el Perú, Maquinaciones, Lima.

Miosi, Blanca (2014): El piso de la calle Ryden y otros cuentos de misterio. [Autoedición electrónica].

Portals Zubiate, Gonzalo (ed.) (2009): La estirpe del ensueño, Narrativa peruana de orientación fantástica, El lamparero alucinado, Lima.

ReIsz, Susana (2014): «Cuando lo fantástico se infiltra en la poesía: hipótesis sobre una relación improbable», en Flavio García, Maria Cristina Batalha y Regina Michelli (eds.), (Re)Visões do Fantástico: do centro ás márgenes; caminhos cruzados, Dialogarts, Río de Janeiro, pp. 173-194.

Richter, Anne (ed.) (1995): Le fantastique féminin: d'Anne Radcliffe à Patricia Highsmith, Complexe, Bruselas.

- (2017): Les écrivains fantastiques féminins et la métamorphose, Académie Royale de Belgique, Bruselas.

Rimachi Sialer, Gabriel, y Carlos Sotomayor (eds.) (2008): 17 fantásticos cuentos peruanos, Casatomada, Lima.

— (eds.) (2012): 17 fantásticos cuentos peruanos, vol. 2, Casatomada, Lima.

RoAs, David (2011): Tras los límites de lo real. Una definición de lo fantástico, Páginas de Espuma, Madrid.

SAla, Rossana (2016): No vaya a despertar a los caballos, Altazor, Lima.

SAlAZAR JiméneZ, Claudia (2016): Coordenadas temporales, Animal de invierno, Lima.

SAldívar, Carlos Enrique (ed.) (2017): Tenebra, muestra de cuentos peruanos de terror, Torre de papel ediciones, Lima. [Edición electrónica]. 
SARTRE, Jean-Paul (1947): Situations I, Gallimard, París.

Serrano, Kathy (2019): «Retorno», Plesiosauro: Primera revista de ficción breve peruana, núm. 11/3, pp. 155-159.

Silva Santisteban, Rocío (2013): Reina del manicomio, Altazor, Lima.

Todorov, Tzvetan (1970): Introduction à la littérature fantastique, Seuil, París. 